\title{
RANCANG BANGUN PROTOTIPE PENGUSIR HAMA BURUNG MENGGUNAKAN SENSOR GERAK RCWL MICROWAVE BERBASIS INTERNET OF THINGS
}

\author{
Nur Hikmah \\ Fakultas Teknik, Program Studi Teknik Informatika \\ Universitas Krisnadwipayana \\ Email: nurhikmah@unkris.ac.id \\ Ali Khumaidi \\ Fakultas Teknik, Program Studi Teknik Informatika \\ Universitas Krisnadwipayana \\ Email: alikhumaidi@unkris.ac.id
}

\begin{abstract}
ABSTRAK
Hama burung pipit merupakan musuh petani dan sulit dikendalikan populasinya. Selama ini pengusirannya menggunakan cara mekanis dengan peralatan tertentu dan tenaga manusia. Pengusiran hama burung pada penelitian sebelumnya untuk deteksi hama menggunakan sensor Passive Infra Red (PIR), sensor ultrasonic, dan Light Dependent Resistor (LDR) serta outputnya berupa gerakan dari motor servo, suara dari kaleng, dan gelombang frekuensi tertentu. Pada penelitian ini menggunakan sensor gerak RCWL Microwave yang memiliki akurasi lebih baik dan outpunya selain gerakan dari motor servo, suara kaleng dari motor DC dan frekuensi dari ultrasonic, juga dilengkapi tembakan laser hijau ke hama burung. Pada penelitian ini menggunakan Arduino Nano ATMega 328, Sensor gerak, Motor Servo, Motor DC, Speaker Ultrasonic, Modul Laser, Power Bank Panel Surya, Modul SIM 800 L. Sistem dapat akses jarak jauh menggunakan aplikasi berbasis desktop dan android. Pengujian yang dihasilkan bahwa sensor gerak dapat mendeteksi dengan baik kumpulan burung, laser hijau masih terlihat pada siang hari, motor servo dapat bergeser hingga $90^{\circ}$, dan speaker ultrasonic berfungsi. Sistem ini akan bekerja optimal jika hama burung dalam bentuk kumpulan dengan lebih dari 5 ekor burung.
\end{abstract}

Kata kunci: hama burung, sensor gerak RCWL, IoT, laser, speaker ultrasonic

\section{ABSTRACT}

Sparrow pests are enemies of farmers and difficult to control the population. So far, the eviction uses mechanical means with certain equipment and human labor. Expulsion of bird pests in previous studies for pest detection using Passive Infra Red (PIR) sensors, ultrasonic sensors, Light Dependent Resistors $(L D R)$ and their output in the form of motions from servo motors, sound from cans, and certain frequency waves. In this study using a RCWL Microwave motion sensor that has better accuracy and output in addition to the movement of the servo motor, the sound of a can from a DC motor and the frequency of ultrasonic, also equipped with green laser shots to bird pests. In this study using Arduino Nano ATMega 328, motion sensors, Servo Motors, DC Motors, Ultrasonic Speakers, Laser Modules, Solar Power Bank Panels, SIM 800 L Module. The system can be accessed remotely using desktop and android based applications. Tests produced that the motion sensor can detect well a collection of birds, green lasers are still visible during the day, servo motors can shift up to $90^{\circ}$, and ultrasonic speakers to function. This system will work optimally if bird pests in the form of a collection with more than 5 birds.

Keywords: sparrow pest, RCWL motion sensor, IoT, laser, ultrasonic speaker 


\section{PENDAHULUAN}

Hama merupakan musuh petani dalam proses penanaman hingga pasca panen. Salah satu hama yang seringkali membuat gagal panen adalah burung pipit, hama ini menyerang ketika menjelang masa panen. Hama ini dapat menyebabkan kerugian yang serius dan biasanya menyerang secara berkelompok mulai puluhan sampai ribuan dari populasinya. Dampak dari serangan hama burung bibit dapat mengakibatkan bulir padi menjadi kering, biji padi hampa, dan biji padi rontok. Pengendalian hama ini biasanya bersifat mekanis memakai peralatan yang dapat mengusir burung pipit, namun terkadang membutuhkan waktu dan kesabaran dalam menunggu di sawah. Bagi yang tidak sempat dapat mengeluarkan biaya yang tidak sedikit untuk jasa pengusirannya namun terkadang tidak optimal. Selain burung pipit terdapat juga hama wereng, tikus dan lainnya.

Hasil kajian literatur menemukan beberapa penelitian sebelumnya terkait pengusiran hama burung pipit. Secara umum penelitian tersebut dapat dikelompokkan berdasarkan input untuk deteksi burung dan outputnya untuk pengusiran burung. Dalam deteksi adanya burung beberapa penelitian menggunakan sensor PIR [1][2][3][4], menggunakan sensor ultrasonic [5][6][7] dan menggunakan cahaya laser dan LDR [8][9]. Hampir semua penelitian outputnya dengan motor servo yang dapat menggerakkan orangorangan sawah atau kaleng yang menimbulkan suara [10][11][12] dan ada yang menggunakan frekuensi ultrasonik [13]. Untuk sumber daya listrik ada yang menggunakan aki, listrik PLN, kombinasi dari Aki dan listrik PLN [14], hingga penggunaan sel surya.

Tujuan penelitian untuk merancang dan membangun prototipe pengusir hama pada sawah berbasis internet of things (IOT). Fokusnya adalah hama burung pipit, dengan penggunaan speaker ultrasonik dengan frekuensi tertentu dapat mengusir hama wereng dan tikus. Prototipe ini terhubung pada jaringan internet yang dapat dimonitor dan dikontrol secara jarak jauh menggunakan desktop dan android. Berdasarkan hasil analisis pada penelitian ini sebagai input menggunakan sensor gerak RCWL Microwave. Hal ini dikarenakan sensor tersebut memiliki tingkat keakuratan lebih baik dalam mendeteksi pergerakan dibanding sensor pendeteksi gerak lainnya seperti sensor PIR dan sensor ultrasonic [15]. Dan output yang kami pilih selain menggunakan motor servo untuk menggerakkan orang-orangan sawah juga ada suara yang dibangkitkan oleh motor DC dan kaleng, kombinasi suara dari speaker ultrasonik untuk mengusir hama wereng dan tikus serta pergerakan dari laser hijau yang membuat burung takut. Dan sebagai catu daya digunakan power bank panel surya karena lebih efisien dan murah.

\section{METODOLOGI PENELITIAN}

Pada penelitian ini menggunakan metode pelaksanaan penelitian seperti pada gambar 1. Penelitian diawali tahap identifikasi masalah dengan melakukan observasi dan wawancara dengan petani di desa binaan Universitas Krisnadwipayana yaitu desa pada kecamatan Cariu yang merupakan lumbung padinya Bogor. Kemudian dilakukan kajian literatur terhadap jurnal dan ebook terkait dengan pengusiran hama padi, mikrokontroller, sensor, dan IOT. Dengan bahan dari 2 tahap sebelumnya kemudian dirancang sistem, topologi dan model komunikasi dari sistem yang akan dibangun. Setelah di peroleh perangkat yang akan digunakan selanjutnya dibuat desain PCB dilanjutkan implementasi hardware dan software dan pengujian. Pengujian menggunakan black box testing dengan menguji fungsi dari tiap hardware dan

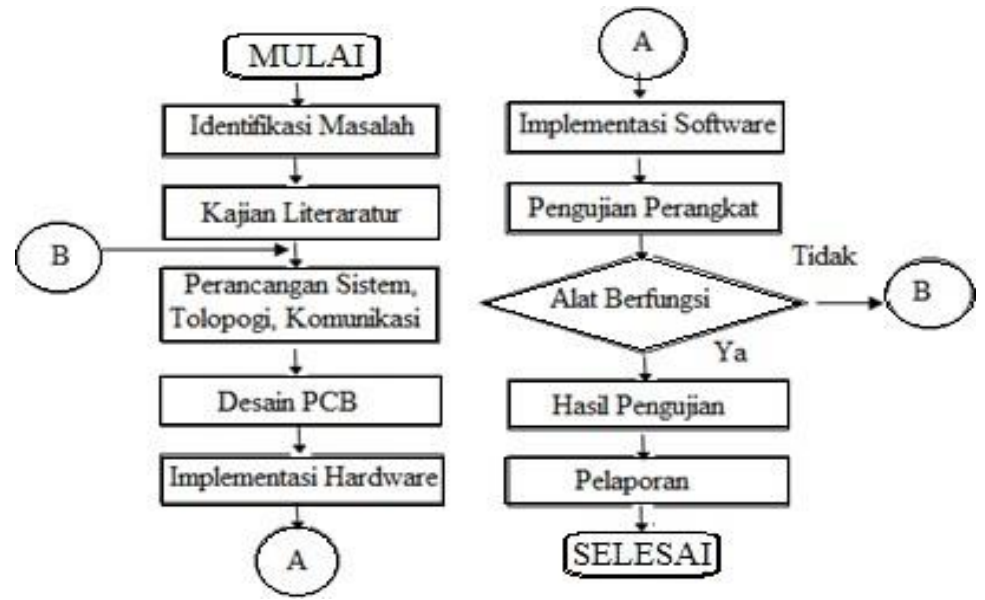


software.

\section{HASIL DAN PEMBAHASAN}

\section{Gambar 1. Flowchart Pelaksanaan Penelitian}

Perancangan sistem ini meliputi komunikasi antar beberapa modul sensor dan alat yang terpasang pada satu orang-orangan sawah, sehingga pengontrolan sawah dari hama burung pipit dapat dilakukan. Gambar 2 adalah desain tata letak peralatan dan perancangan sistem yang akan dibuat terlihat pada gambar 3. Untuk komunikasi menggunakan jaringan internet wifi, dimana modul SIM800L terhubung ke internet. Untuk mengakses informasi dan mengontol beberapa sensor peralatan bisa menggunakan smartphone atau menggunakan PC dengan mengakses melalui web browser.

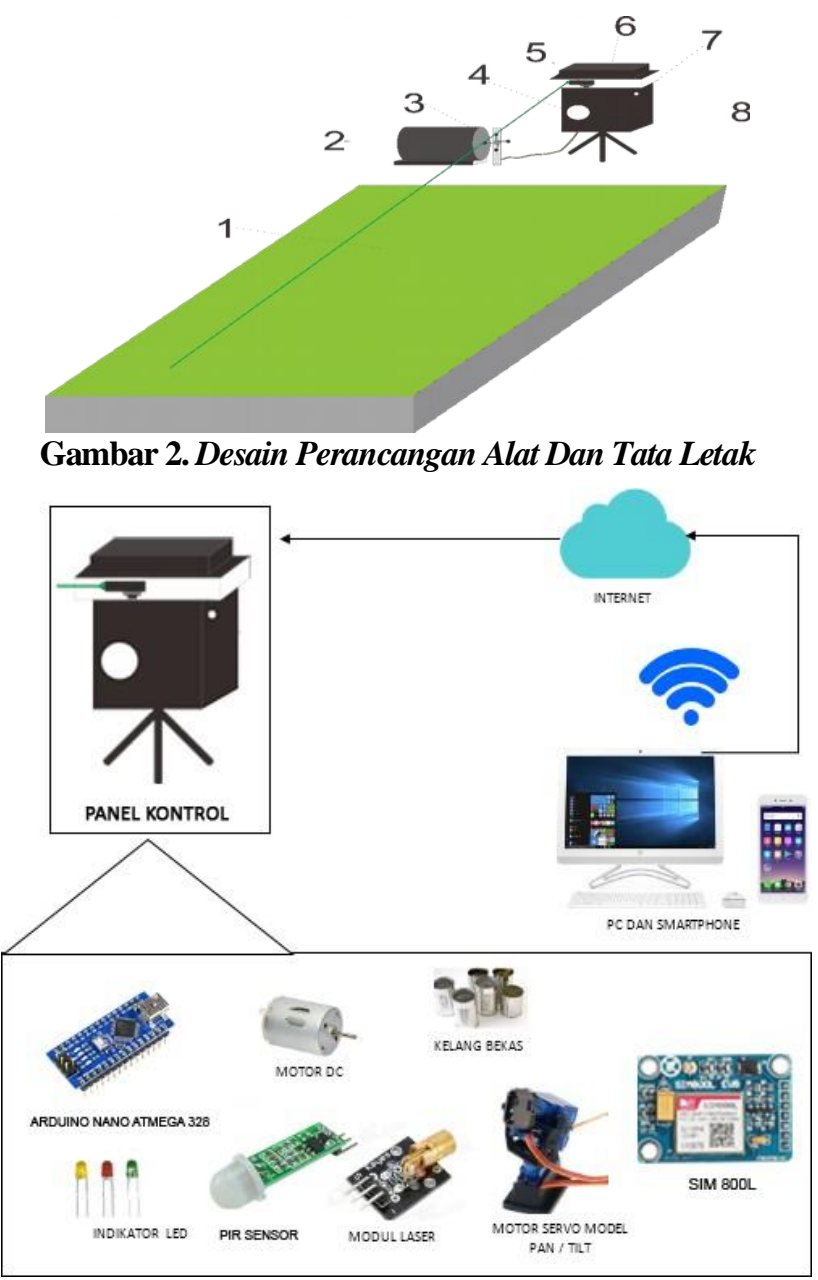

Gambar 3. Desain Perancangan Sistem

Rancangan kerja sistem merupakan gambaran mengenai cara kerja sistem yang dibuat. Flowchart pada gambar 4 mewakili cara kerja, alur kerja serta beberapa fungsi yang akan dijalankan pada sistem. Sebelum tahap impelmentasi diperlukan beberapa perangkat keras (Hardware) dan perangkat lunak (Software) pada tabel 1 .

Tabel 1. Daftar Kebutuhan Pengembangan Prototipe 


\begin{tabular}{ll}
\hline Hardware & Software \\
\hline 1. Arduino Nano ATMega 328 & 1. Arduino IDE \\
2. Sensor gerakRCWL Microwave & 2. Sublime Text 3 \\
3. Motor Servo, Motor DC & 3. Web Browser \\
4. Speaker Ultrasonic & 4. Bahasa pemrograman HTML, PHP, \\
5. Modul Laser & JavaScript dan C++ \\
6. Power Bank Panel Surya & 5. MySql \\
7. Modul SIM 800 L & \\
8. Relay, LED, LCD & \\
\hline
\end{tabular}

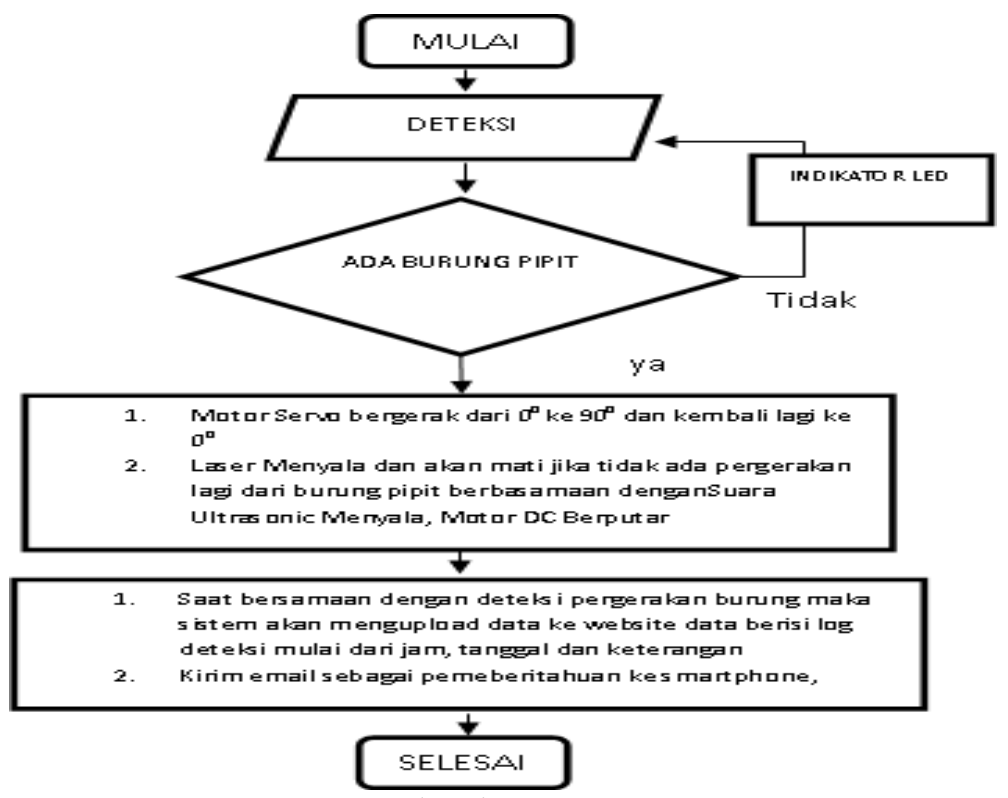

Gambar 4. Flowchart Cara Kerja Sistem

Tahap berikutnya adalah implementasi hardware yang langkah kerja dan aktivitasnya terlihat pada tabel 2 .

Tabel 2. Implementasi Hardware

\begin{tabular}{|c|l|c|}
\hline No & Aktivitas Kerja & Keterangan Gambar \\
\hline 1 & Perakitan PCB dan komponen pendukung. & \\
& Resistor bertujuan untuk memberikan ke stabilan \\
& pin (kaki IC) yang dijadikan sensor maupun \\
& button dengan input high (diberikan tegangan \\
& positif 5v) & \\
\hline 2 & Perakitan saklar (switch), perakitan switch & \\
& momentary yang dijadikan tombol untuk & 2 \\
& menyalakan keseluruhan alat, penerang layar & \\
& LCD dan Indikator LED yang akan ditempatkan & \\
& pada box panel perangkat & \\
\end{tabular}




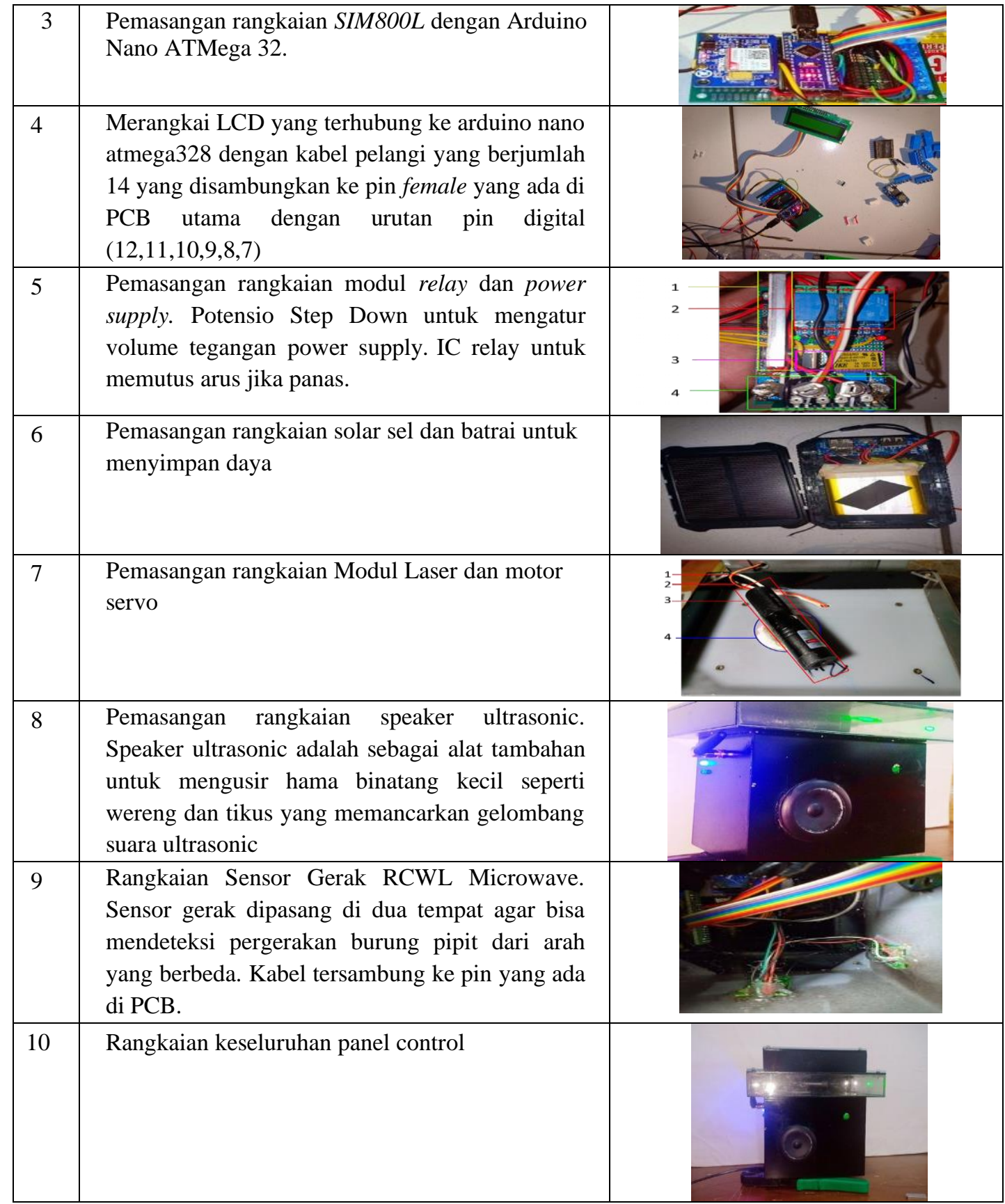

Sedangkan pada implementasi software langkah-langkahnya sebagai berikut:

1. Inslatasi Arduino IDE, MySql, Sublime Text 3, Web browser, App Inventor dan koneksi ThingSpeak

2. Pembuatan database

3. Pemberian logika melalui kode program (source code) pada perangkat keras

4. Pembuatan interface 
Berikutnya adalah pengujian terhadap hardware dan software. Hasil pengujian hardware terlihat pada tabel 3 dan tabel 4 adalah hasil pengujian software.

Tabel 3. Hasil Pengujian Hardware

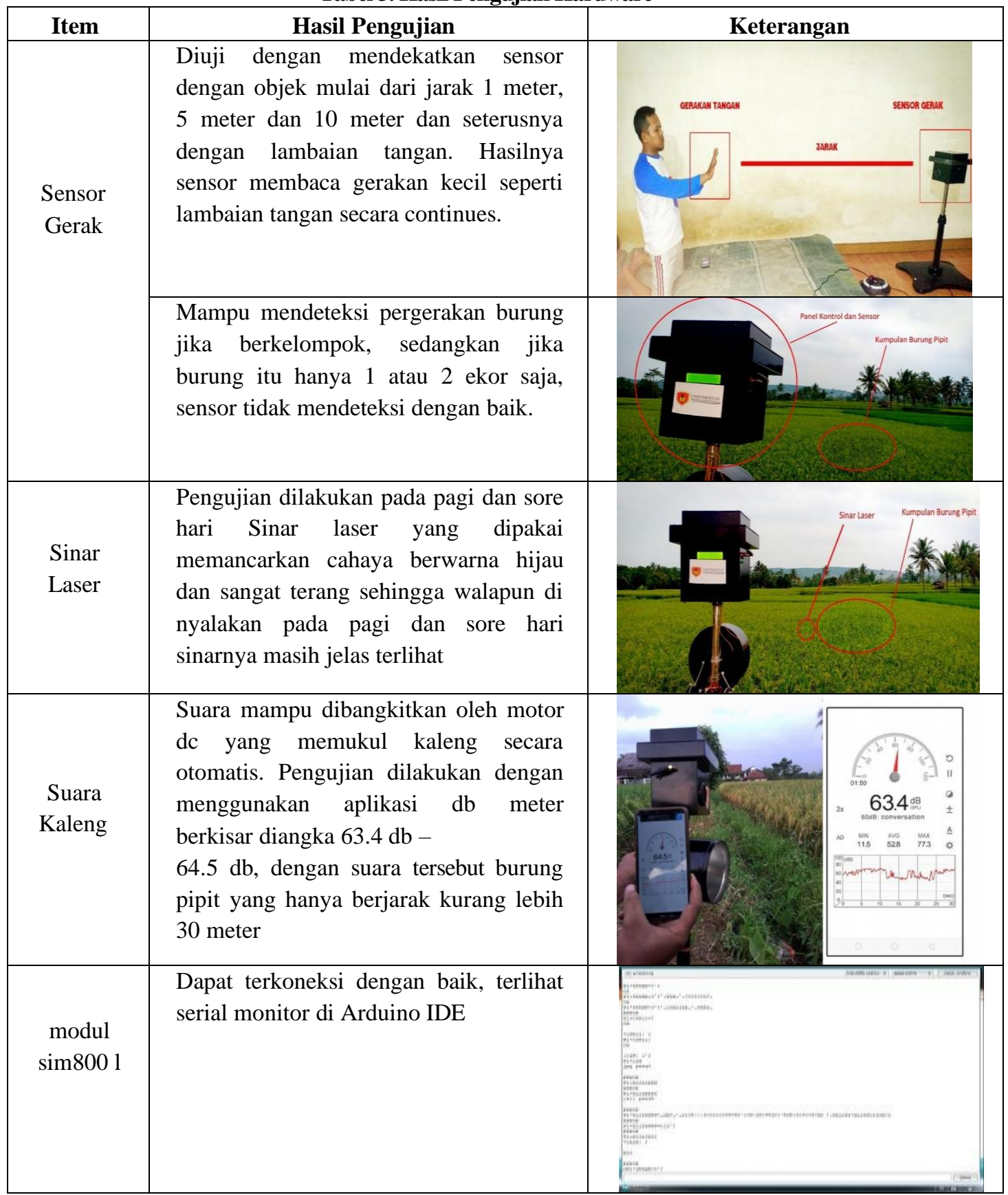




\begin{tabular}{|c|c|}
\hline $\begin{array}{l}\text { Motor } \\
\text { Servo }\end{array}$ & $\begin{array}{l}\text { Motor servo berhasil melakukan } \\
\text { pergeseran derajat dari } 0^{\circ} \text { ke } 90^{\circ} \\
\text { dengan waktu delay } 50 \text { miscosecond } \\
\text { sesuai program. Pegukuran dengan } \\
\text { bantuan busur derajat untuk } \\
\text { mencocokkan besar pergeseran. }\end{array}$ \\
\hline
\end{tabular}

Tabel 4. Hasil Pengujian Software

\begin{tabular}{|c|l|}
\hline Dashboard & $\begin{array}{l}\text { Script dari JavaScript dapat bekerja } \\
\text { dengan baik dengan script php dan } \\
\text { dapat menerjemah segala perintah dan } \\
\text { dapat berkomunikasi dengan arduino } \\
\text { yang menggunakan bahasa C++ }\end{array}$ \\
\hline Web & $\begin{array}{l}\text { Semua fungsi pada aplikasi berjalan } \\
\text { dengan baik dan mampu melakukan } \\
\text { pembacaan data yang terkirim secara } \\
\text { realtime dan update otomatis. }\end{array}$ \\
\hline Android & $\begin{array}{l}\text { Aplikasi android telah berjalan dengan } \\
\text { baik dan sesuai dengan aplikasi yang } \\
\text { ada di web browser dashboard }\end{array}$ \\
\hline
\end{tabular}

Hasil dari pengujian hardware dan software bahwa alat dan dashbord telah bekerja dengan baik. Sensor gerak dan modul laser akan bekerja terhadap pengusiran burung secara optimal jika dalam kondisi berkelompok dengan minimal 5 ekor burung. Dari hasil percobaan bahwa jika jumlah burung hanya kurang dari 5 maka sensor kurang respon, dan jika jika hanya 1 burung pipit sensor tidak dapat mendeteksi. Namun dikarenakan sifat alamiah burung pipit yang berkelompok maka secara keseluruhan dalam pengujian dilapangan telah berhasil mengusir kumpulan burung dengan adnya sinar laser, gerakan dari orang- orangan sawah, suara kaleng dan speaker ultrasonic.

\section{KESIMPULAN}

Pengembangan prototipe pengusir hama burung menggunakan Arduino Nano ATMega 328, Sensor gerakRCWL Microwave, Motor Servo, Motor DC, Speaker Ultrasonic, Modul Laser, Power Bank Panel Surya, Modul SIM 800 L, Relay, LED, LCD berhasil dirakit dan diujicoba. Aplikasi desktop dan android terkoneksi dan berhasil melakukan pengiriman data. Sensor gerak RCWL Microwave mampu mendeteksi secara optimal terhadap kumpulan burung dengan minimal 5 ekor. Modul laser hijau masih terlihat pancarannya dan berhasil mengusir kuumpulan burung. Kobinasi suara kaleng, pergerakan dan speaker ultrasonic sangat baik dalam pengusiran hama burung serta hama wereng dan tikus. 


\section{UCAPAN TERIMA KASIH}

Kami ucapkan terimakasih kepada Pimpinan Fakultas Teknik UNKRIS yang sudah support untuk sarana dan prasarana dalam enelitian, Tim Laboratorium IoT Prodi Informatika, bang Wandi dan bang Ji yang sangat membantu selama perakitan serta pengujian. Serta Editor dan Reviewer Jurnal SIMETRIS yang memberikan review dan koreksi hingga artikel ini dapat terpublikasi..

\section{DAFTAR PUSTAKA}

[1] Rahim. M.A., Sulo. B.D., and Alawiy. M.T., "Pengendali Hama Burung Dan Serangga Menggunakan Suara Dan Lampu Ultraungu Bertenaga Surya," Sci. Electro, vol. 10, no. 1, pp. 55-63, 2019.

[2] Alfriadi. A, Permana A.G., and Ramadan D.N., "Perancangan Dan Implementasi OrangOrangan Sawah Pengusir Hama Menggunakan Pir Dan Mikrokontroler," e- Proceeding Appl. Sci., vol. 4, no. 3, pp. 2594-2600, 2018.

[3] Laksono A.B. and Zahidi A.R., "Rancang Bangun Alat Pengusir Burung Pemakan Padi Berbasis Mikrokontroller Atmega328 Dengan Sel Surya,” J. JE- Unisla, vol. 2, no. 1, pp. $1-4,2017$.

[4] Bayu. P.W, "Internet Of Things Pengusir Hama Burung Pemakan Padi Dengan Kendali Raspberry Pi,” Universitas Muhammadiyah Ponorogo, 2018.

[5] N. I. Adhitya, "Prototipe Alat Pengusir Hama Burung Pemakan Padi Disawah Berbasis Arduino Uno,” J. Elektron. Pendidik. Tek. Elektron., vol. 7, no. 3, pp. 67-78, 2018.

[6] T. Silvia, "Rancang Bangun Alat Penghalau Hama Burung Berbasis Arduino Uno. Skripsi," Politeknik Ati Makassar, 2018.

[7] Halim A, "Rancang Bangun Alat Pengusir Hama Tanaman Menggunakan Gelombang Ultrasonik Dengan Variasi Letak Dan Jumlah Sumber Gelombang," Politeknik Ati Makassar, 2018.

[8] Sumariadi, Wildian, and Y. M, “Aplikasi Mikrokontroler At89s52 Sebagai Pengontrol Sistem Pengusir Burung Pemakan Padi Dengan Bunyi Sirine," J. Fis. Unand, vol. 2, no. 1, pp. 64-71, 2013.

[9] Tuluk E., Buyung I., and Soejono A.W., "Implementasi Alat Pengusir Hama Burung Di Area Persawahan Dengan Menggunakan Gelombang Ultrasonik Berbasis Mikrokontroler Atmega168," J. Teknol. Inf., vol. 7, no. 1, pp. 121-134, 2012.

[10] Syahminan, "Prototype Pengusir Burung Pada Tanaman Padi Berbasis Mikrokontroler Aurdino,” J. SPIRIT, vol. 9, no. 2, pp. 26-34, 2017.

[11] Nugroho A.A., "Prototipe Sistem Pengusir Hama Burung Berbasis Computer Vision," Universitas Sanata Dharma Yogyakarta, 2018.

[12] Yanuar A. Z, "Prototype Alat Pengusir Hama Burung Berbasis Mikrokontroler Atmega8," Universitas Negeri Yogyakarta, 2012.

[13] Rainaldi R, “Alat Pengendali Hama Padi Berbasis Internet Of Things (IOT), " Universitas Andalas, 2019.

[14] Oktivira. A.L. and Kholis N, "Prototype Sistem Pengusir Hama Burung Dengan Catu Daya Hybrid Berbasis IOT,” J. Tek. Elektro, vol. 9, no. 1, pp. 735-741, 2019. 
[15] Q. Aini, U. Rahardja, H. Madiistriyatno, and F. Azharul, "Rancang Bangun Alat Monitoring Pergerakan Objek pada Ruangan Menggunakan Modul RCWL 0516," J. Tek. Elektro, vol. 10, no. 1, pp. 41-46, 2018. 